\title{
Urolitíase em 76 cães ${ }^{1}$
}

\author{
Maria Andréia Inkelmann², Glaucia D. Kommers ${ }^{3 *}$, Maria Elisa Trost ${ }^{2}$, Claudio S.L. \\ Barros $^{3}$, Rafael A. Fighera ${ }^{3}$, Luiz Francisco Irigoyen ${ }^{3}$ e Isadora P. Silveira ${ }^{4}$
}

\begin{abstract}
Inkelmann M.A., Kommers G.D., Trost M.E., Barros C.S.L., Fighera R.A., Irigoyen L.F. \& Silveira I.P. 2012. [Urolithiasis in 76 dogs.] Urolitíase em 76 cães. Pesquisa Veterinária Brasileira 32(3):247-253. Departamento de Patologia, Universidade Federal de Santa Maria, Av. Roraima 1000, Santa Maria, RS 97105-900, Brazil. E-mail: glaukommers@yahoo.com

From January 1990 to December 2010, 4,872 dogs were necropsied at the Laboratório de Patologia Veterinária, Universidade Federal de Santa Maria. Seventy six dogs (1.6\%) had uroliths along the urinary tract. The epidemiological profile of the affected dogs showed predominance of males (64.5\%); adults (52.6\%); and pure breeds (56.6\%). Clinical signs suggestive of urolithiasis were reported in $30.3 \%$ of the dogs and consisted mainly of hematuria, anuria, dysuria and urinary incontinency. The uroliths were found in one or more anatomical sites, and the main affected ones (in descending order) were urinary bladder, kidney, and urethra. Ureteral urolithiasis was not observed. Secondary lesions to urolithiasis were found in about $40 \%$ of the cases. The most prevalent (in descending order) were cystitis, urethral obstruction, hydroureter, hydronephrosis, urinary bladder rupture (with uroperitoneum), and pyelonephritis. In $25 \%$ of the affected dogs, spontaneous death occurred or euthanasia was performed due to the secondary lesions of urolithiasis. Extrarenal lesions of uremia were found in $11.8 \%$ of the cases.
\end{abstract}

INDEX TERMS: Diseases of dogs, diseases of the urinary tract, pathology, urolithiasis.

RESUMO.- Entre janeiro de 1990 e dezembro de 2010 foram necropsiados 4.872 cães no Laboratório de Patologia Veterinária da Universidade Federal de Santa Maria (LPV-UFSM). Destes, 76 (1,6\%) apresentaram urólitos em algum local do sistema urinário. 0 perfil epidemiológico dos cães afetados demonstrou o predomínio de machos (64,5\%), adultos $(52,6 \%)$ e com raça definida $(56,6 \%)$. Sinais clínicos indicativos de urolitíase foram reportados em 30,3\% dos casos e consistiram principalmente de hematúria, anúria, disúria e incontinência urinária. Os urólitos tiveram localização única ou múltipla e os locais anatômicos mais frequentemente acometimentos, em ordem decrescente de

\footnotetext{
${ }^{1}$ Recebido em 30 de novembro de 2011.

Aceito para publicação em 28 de dezembro de 2011.

Parte da tese de doutorado do primeiro autor.

${ }^{2}$ Programa de Pós-Graduação em Medicina Veterinária, área de concentração em Patologia Veterinária, Centro de Ciências Rurais (CCR), Universidade Federal de Santa Maria (UFSM), Camobi, Santa Maria, RS 97105900, Brasil.

${ }^{3}$ Departamento de Patologia, Centro de Ciências da Saúde, UFSM, Av. Roraima 1000, Santa Maria, RS 97105-900. *Autor para correspondência: glaukommers@yahoo.com

${ }^{4}$ Curso de Medicina Veterinária, CCR-UFSM, Santa Maria, RS. Bolsista PIBIC/CNPq/UFSM.
}

frequência, foram: bexiga, rim e uretra. Urolitíase ureteral não foi observada. Lesões secundárias à urolitíase foram observadas em aproximadamente $40 \%$ dos cães afetados; as mais prevalentes, em ordem decrescente de frequência, foram: cistite, obstrução uretral, hidroureter, hidronefrose, ruptura vesical (com uroperitônio) e pielonefrite. Em 25\% dos cães afetados ocorreu morte espontânea ou eutanásia decorrente das lesões secundárias à urolitíase. Lesões extra-renais de uremia foram observadas em $11,8 \%$ dos casos.

TERMOS DE INDEXAÇ̃̃O: Doenças de cães, doenças do trato urinário, patologia, urolitíase.

\section{INTRODUÇÃO}

Urolitíase é caracterizada pela presença de urólitos (cálculos, concreções ou pedras) ao longo do trato urinário (Maxie \& Newman 2007, Osborne et al. 2008). Urólitos podem ser formados em qualquer local do sistema urinário, desde a pelve renal até a uretra (Osborne 2008, Neta \& Munhoz 2008) e são constituídos por agregados de solutos urinários, precipitados e organizados em um núcleo central (ninho ou núcleo de cristal), que, por sua vez, é circundado por lâminas concêntricas e por cristais de superfície (Maxie \& Newman 2007, Newman et al. 2007). 
Predisposição familiar e/ou racial, defeitos congênitos e lesões adquiridas podem favorecer a formação de cálculos no trato urinário de cães (Osborne et al. 2008). 0 tipo de alimentação também é incriminado em facilitar a formação ou inibir a dissolução dos urólitos (Osborne \& Lulich 2004, Monferdini \& Oliveira 2009). Cães com anomalias vasculares portais, hiperparatireoidismo primário, hipercalcemia ou hiperadrenocorticismo são predispostos à formação de urólitos (Maxie \& Newman 2007). A administração de diversos medicamentos, como acidificantes e alcalinizantes da urina, antibióticos, quimioterápicos e corticosteroides, podem também contribuir para a ocorrência de urolitíase (Osborne et al. 2008).

Doenças causadas por urólitos estão entre os problemas mais importantes do trato urinário dos animais domésticos (Maxie \& Newman 2007, Newman et al. 2007) e podem culminar em morte. Extensas lesões secundárias podem formar-se rapidamente no sistema urinário, principalmente se os cálculos causarem obstrução parcial ou completa do fluxo urinário. Entretanto, urólitos não-obstrutivos podem persistir por longo tempo sem causar qualquer tipo de lesão nem serem percebidos clinicamente (Osborne et al. 1996, Maxie \& Newman 2007, Newman et al. 2007, Neta \& Munhoz 2008).

A prevalência clínica da urolitíase em cães varia de $0,5 \%$ a $1 \%$. Nos Estados Unidos, estudos demonstraram que a urolitíase em cães é a terceira alteração mais relatada no trato urinário inferior (Lulich et al. 2004). Os objetivos deste estudo retrospectivo foram: 1) determinar a prevalência da urolitíase em cães na Região Central do Rio Grande do Sul, 2) estabelecer suas características clínico-epidemiológicas e os tipos de lesões secundárias no trato urinário, 3) reconhecer sua importância clínica e 4) descrever a morfologia e a localização anatômica dos urólitos em cães necropsiados no LPV-UFSM num período de 21 anos.

\section{MATERIAL E MÉTODOS}

Foram revisados os protocolos de necropsias de cães realizadas no LPV-UFSM durante o período de janeiro de 1990 a dezembro de 2010. Somente casos de cães que apresentavam urólitos no momento da necropsia foram selecionados.

Do total de casos encontrados, foram anotados os dados referentes à epidemiologia (sexo, idade e raça), aos sinais clínicos (associados ou não à presença de urólitos), à localização anatômica no trato urinário, ao aspecto macroscópico dos cálculos, à ocorrência de lesões secundárias aos urólitos, à ocorrência de lesões extra-renais de uremia e à importância clínica (se achado incidental ou causa da morte/razão para eutanásia). Em relação à faixa etária, os cães foram classificados como filhotes (menos de um ano de idade), adultos (1-9 anos de idade) ou idosos (10 anos de idade ou mais), conforme previamente realizados por Fighera et al. (2008).

Não foram considerados os casos em que apenas discreto sedimento arenoso vesical ou uretral foi descrito nos protocolos de necropsia.

\section{RESULTADOS}

Do total de 4.872 cães necropsiados no LPV-UFSM no período de 21 anos, $76(1,6 \%)$ apresentaram urólitos no sistema urinário. Os dados clínico-epidemiológicos dos 76 cães com urolitíase estão resumidos no Quadro 1.

\section{Quadro 1. Dados clínico-epidemiológicos de 76 cães com urolitíase necropsiados no Laboratório de Patologia Veterinária da Universidade Federal de Santa Maria (LPV-UFSM) no período de janeiro de 1990 a dezembro de 2010}

\begin{tabular}{cccc}
\hline $\begin{array}{c}\text { Sexo } \\
(\mathrm{n} / \%)\end{array}$ & $\begin{array}{c}\text { Faixa etária } \\
(\mathrm{n} / \%)\end{array}$ & $\begin{array}{c}\text { Raça } \\
(\mathrm{n} / \%)\end{array}$ & $\begin{array}{c}\text { Histórico clínico } \\
(\mathrm{n} / \%)\end{array}$ \\
\hline $\mathrm{F}^{\mathrm{a}}(27 / 35,5)$ & Filhotes $(4 / 5,3)$ & Definida $(43 / 56,6)$ & $\mathrm{R}^{\mathrm{b}}\left(23^{\mathrm{c}} / 30,3\right)$ \\
$\mathrm{M}^{\mathrm{d}}(49 / 64,5)$ & $\begin{array}{c}\text { Adultos }(40 / 52,6) \\
\text { Idosos }(30 / 39,5) \\
\mathrm{NI}^{\mathrm{h}}(2 / 2,6)\end{array}$ & $\mathrm{SRD}^{\mathrm{e}}(33 / 43,4)$ & $\mathrm{NR}^{\mathrm{f}}(47 / 61,8)$ \\
& & $\mathrm{NC}^{\mathrm{g}}(6 / 7,9)$ \\
& &
\end{tabular}

${ }^{\mathrm{a}} \mathrm{F}$ = fêmea; ${ }^{\mathrm{b}} \mathrm{R}=$ relacionado à urolitíase; ${ }^{\mathrm{c}}$ Dos 23 cães, 16 tiveram morte espontânea; ${ }^{\mathrm{d}} \mathrm{M}=$ macho; ${ }^{\mathrm{e}} \mathrm{SRD}=$ sem raça definida; ${ }^{\mathrm{f}} \mathrm{NR}=$ não relacionado à urolitíase; ${ }^{\mathrm{g}} \mathrm{NC}=$ não consta; ${ }^{\mathrm{h}} \mathrm{NI}=$ não informado.

A grande maioria $(64,5 \%)$ dos cães afetados era constituída por machos. A idade variou entre 45 dias e 16 anos. Cães adultos $(52,6 \%)$ predominaram sobre os idosos $(39,5 \%)$ e filhotes $(5,3 \%)$. A maioria $(56,6 \%)$ dos cães afetados tinha raça definida. As raças mais prevalentes, em ordem decrescente de frequência, foram: Pastor Alemão (11 [14,5\%]), Poodle (5 [6,6\%]), Dálmata (4 [5,2\%]), Yorkshire Terrier (4 [5,2\%]), Boxer (3 [3,9\%]), Collie (2 [2,6\%]), Dachshund (2 [2,6\%]), Fila Brasileiro (2 [2,6\%]), Rottweiler (2 [2,6\%]), Basset Hound (1 [1,3\%]), Cocker Spaniel Inglês (1 [1,3\%]), Dogue de Bourdeaux (1 [1,3\%]), Labrador Retriever (1 [1,3\%]), Lhasa Apso (1 [1,3\%]), Pastor Belga (1 [1,3\%]), Pequinês (1[1,3\%]) e Pinscher $(1[1,3 \%])$.

Em 23 dos 76 cães (30,3\%), o histórico clínico indicava a presença de urólitos. Os principais sinais clínicos descritos nos históricos e relacionados com a urolitíase foram, em ordem decrescente de frequência: hematúria, anúria, disúria e incontinência urinária. Em alguns desses cães foram realizados exames radiográficos que resultaram na identificação de imagens compatíveis com urolitíase renal, vesical ou uretral. Em 52 cães $(68,4 \%)$ a morte foi espontânea, em 19 (25\%) foi realizada a eutanásia e em cinco casos $(6,6 \%)$ não havia informação a respeito da morte.

A localização anatômica dos urólitos compreendeu os rins (uni ou bilateralmente), a bexiga e a uretra (Figs.1-6) e a sua distribuição encontra-se sumarizada no Quadro 2 . Urolitíase ureteral não foi observada. Em 60 cães $(78,9 \%)$ apenas um dos segmentos do trato urinário estava afetado por um ou por vários urólitos. Em 38 cães (50\%) os cálculos estavam localizados somente na bexiga. 0 acometimento único da pelve renal $(14 / 76$ [18,4\%]) foi o segundo mais prevalente, seguido pela uretra $(10,5 \%[8 / 76])$. Treze cães $(17,1 \%)$ apresentavam as concreções em dois locais do trato urinário e em apenas três casos $(3,9 \%)$, rim, bexiga e uretra continham cálculos simultaneamente. 0 acometimento da bexiga, rim e uretra manteve essa mesma ordem decrescente de prevalência também quando foram somadas todas as ocorrências em cada local (localização única ou múltipla) ao longo do trato urinário.

A maior parte dos protocolos de necropsia continha descrição macroscópica dos urólitos encontrados no trato urinário. Eles eram sólidos; geralmente duros; redondos, ovais, facetados ou irregulares; lisos ou rugosos (às vezes com múltiplas projeções pontiagudas); brancos, branco-amarelados, amarelos, marrons, marrom-esverdeados ou verdes. Na be- 


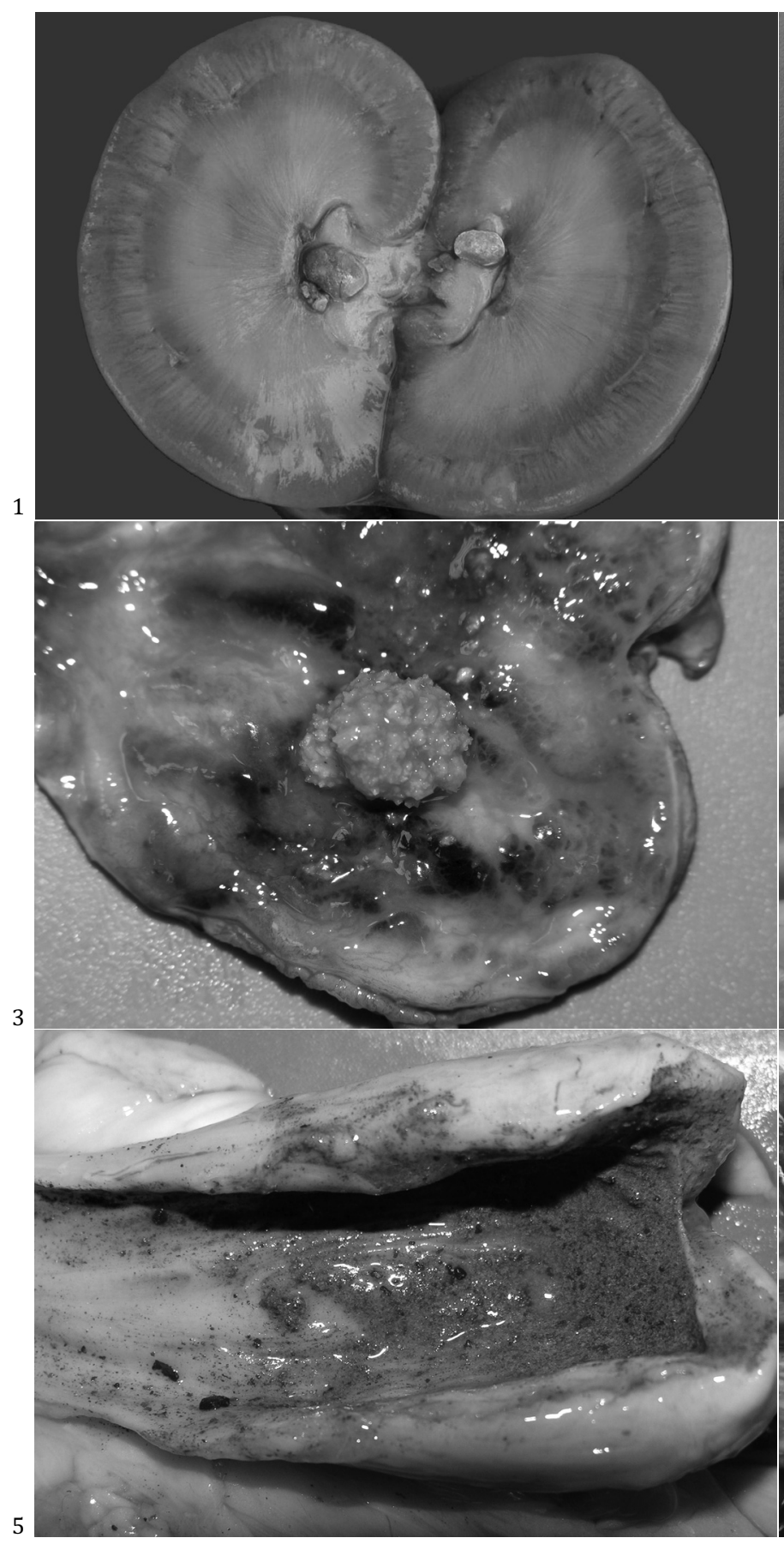

Fig.1. Nefrólitos. Observam-se múltiplos cálculos ovais e marrom-acinzentados na pelve renal.

Fig.3. Urocistólito. Na luz vesical há um cálculo branco-amarelado e irregular com numerosas projeções pontiagudas. Cistite necro-hemorrágica, multifocal e moderada secundária à urolitíase também é observada.

Fig.5. Urocistólitos. Grande quantidade de material arenoso esverdeado, entremeado por pequenos e múltiplos cálculos verde-escuros, é observada na luz vesical.

xiga, onde predominaram, eles eram de diversos tamanhos e múltiplos na maioria dos casos. Entretanto, poucos casos de grandes urólitos vesicais únicos foram também observados.

Dos 76 cães com urolitíase, trinta $(39,5 \%)$ tiveram lesões secundárias (Figs.7-12). Nos demais casos (46/76
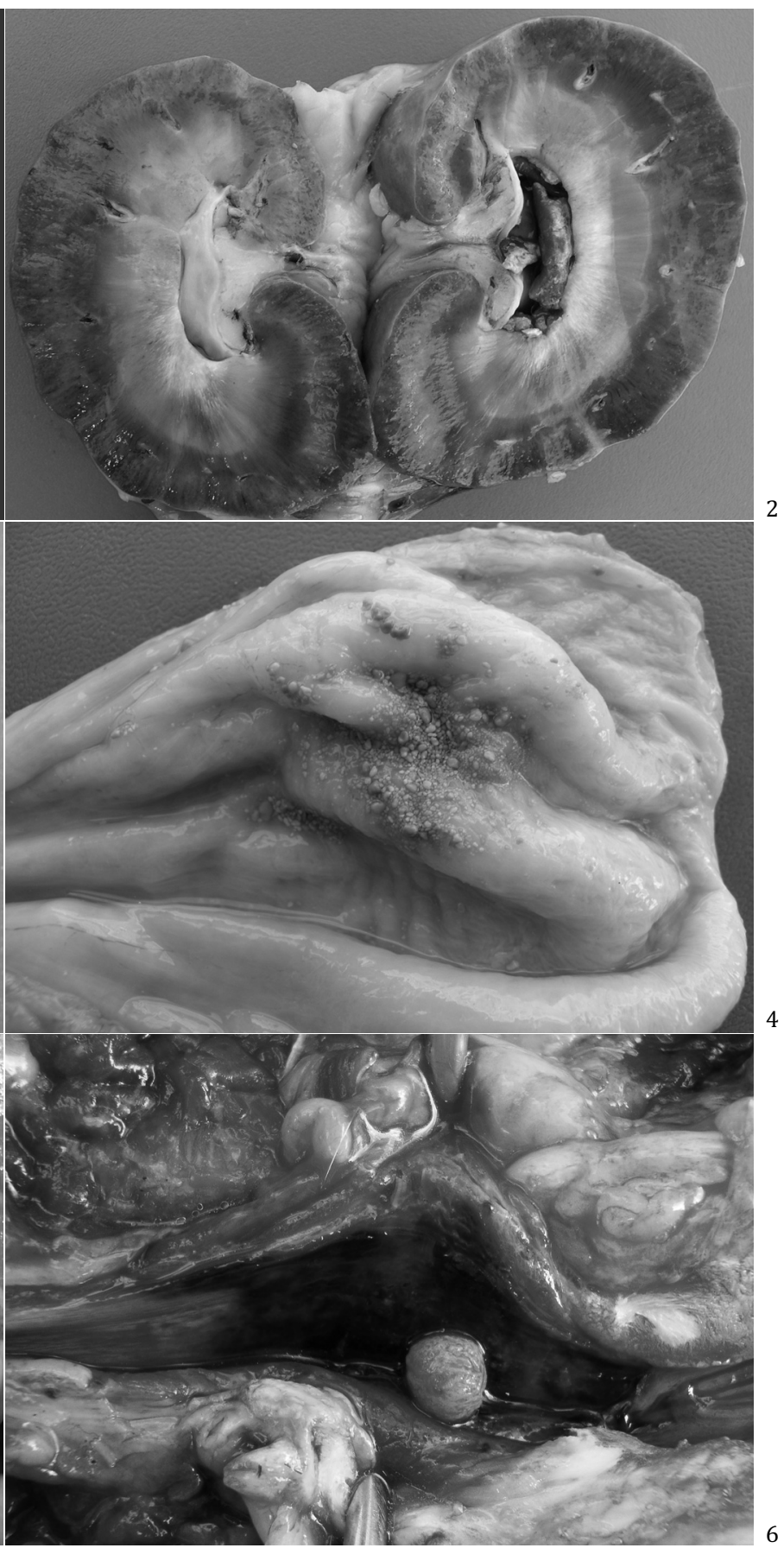

Fig.2. Nefrólitos. Há múltiplos cálculos irregulares e marrom-esverdeados na pelve renal que está levemente dilatada. 0 parênquima renal está firme e a superfície subcapsular irregular devido à nefrite intersticial crônica concomitante e não relacionada.

Fig.4. Urocistólitos. Pequenos e múltiplos cálculos amarelo-alaranjados são observados na luz vesical.

Fig.6. Uretrólito. Obstruindo parcialmente a luz uretral, na base do osso peniano, há um cálculo de $0,5 \mathrm{~cm}$ de diâmetro, com superfície irregular e amarela. Há uretrite fibrino-hemorrágica associada.

[60,5\%]), a presença dos urólitos foi considerada um achado incidental de necropsia. Os tipos de lesões secundárias à presença dos urólitos em diferentes localizações estão detalhados no Quadro 2. Elas foram observadas como lesões secundárias únicas ou em diversas combinações, num 


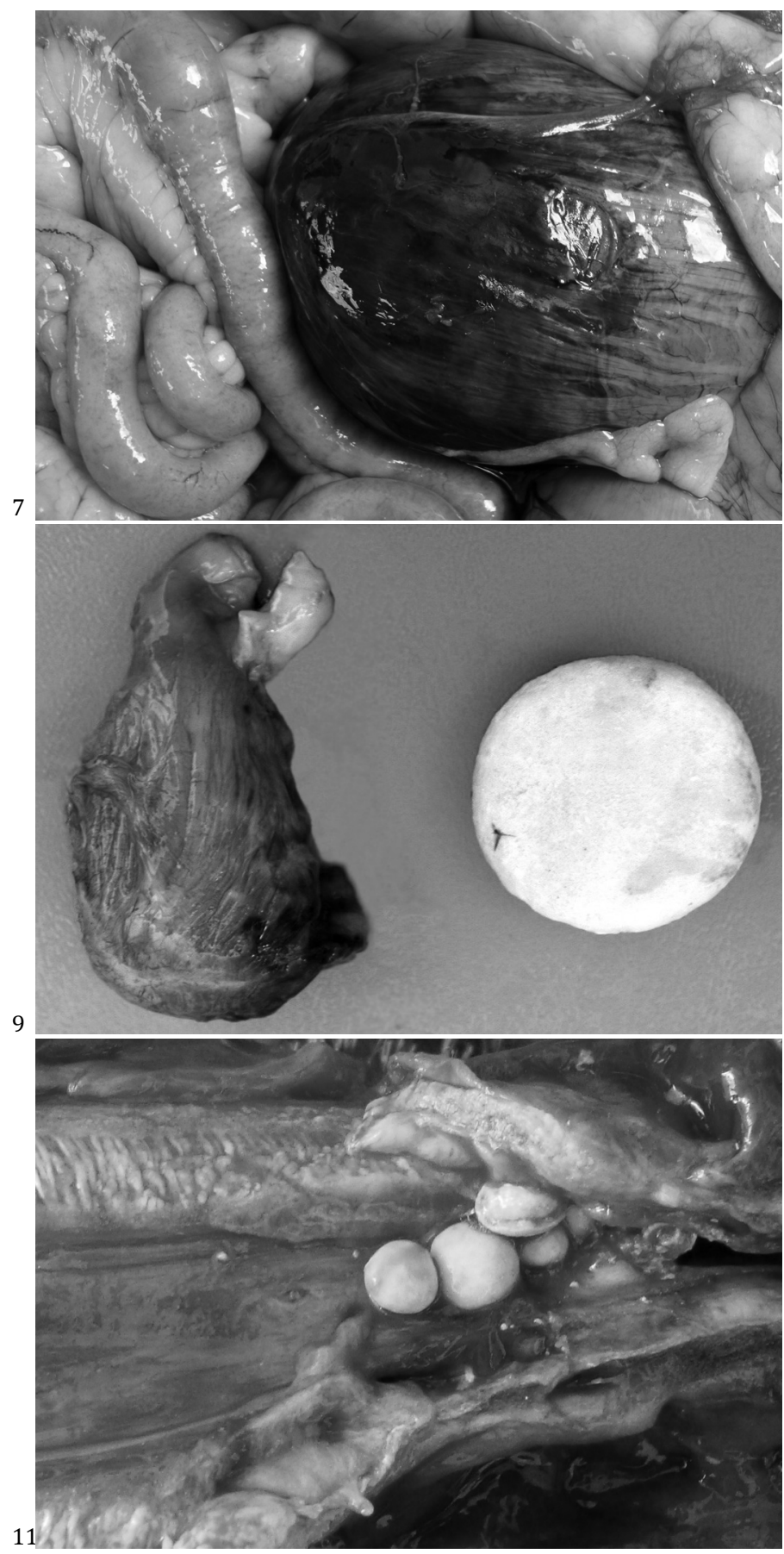

Fig.7. Cistite necro-hemorrágica secundária à uretrólito (cão da Figura 6). A serosa está vermelho-escura e com vasos superficiais hiperêmicos.

Fig.9. Ruptura vesical e urocistólito. A bexiga tem a parede rompida e hemorragia na serosa. Ao lado está um cálculo grande, branco-amarelado, liso, redondo e achatado $(3 \mathrm{~cm}$ de diâmetro) que encontrava-se livre na cavidade abdominal.

Fig.11. Ruptura uretral e uretrólitos. Há vários cálculos redondos, amarelos e lisos, com até $0,5 \mathrm{~cm}$ de diâmetro na uretra. Há ruptura da parede uretral na base do osso peniano, onde os cálculos estão alojados. Há inflamação, necrose e hemorragia nos tecidos que circundam a uretra rompida.

total de 78 ocorrências, distribuídas na seguinte ordem decrescente de frequência: cistite (predominantemente necro-hemorrágica) (18/76 [23,7\%]); obstrução uretral,

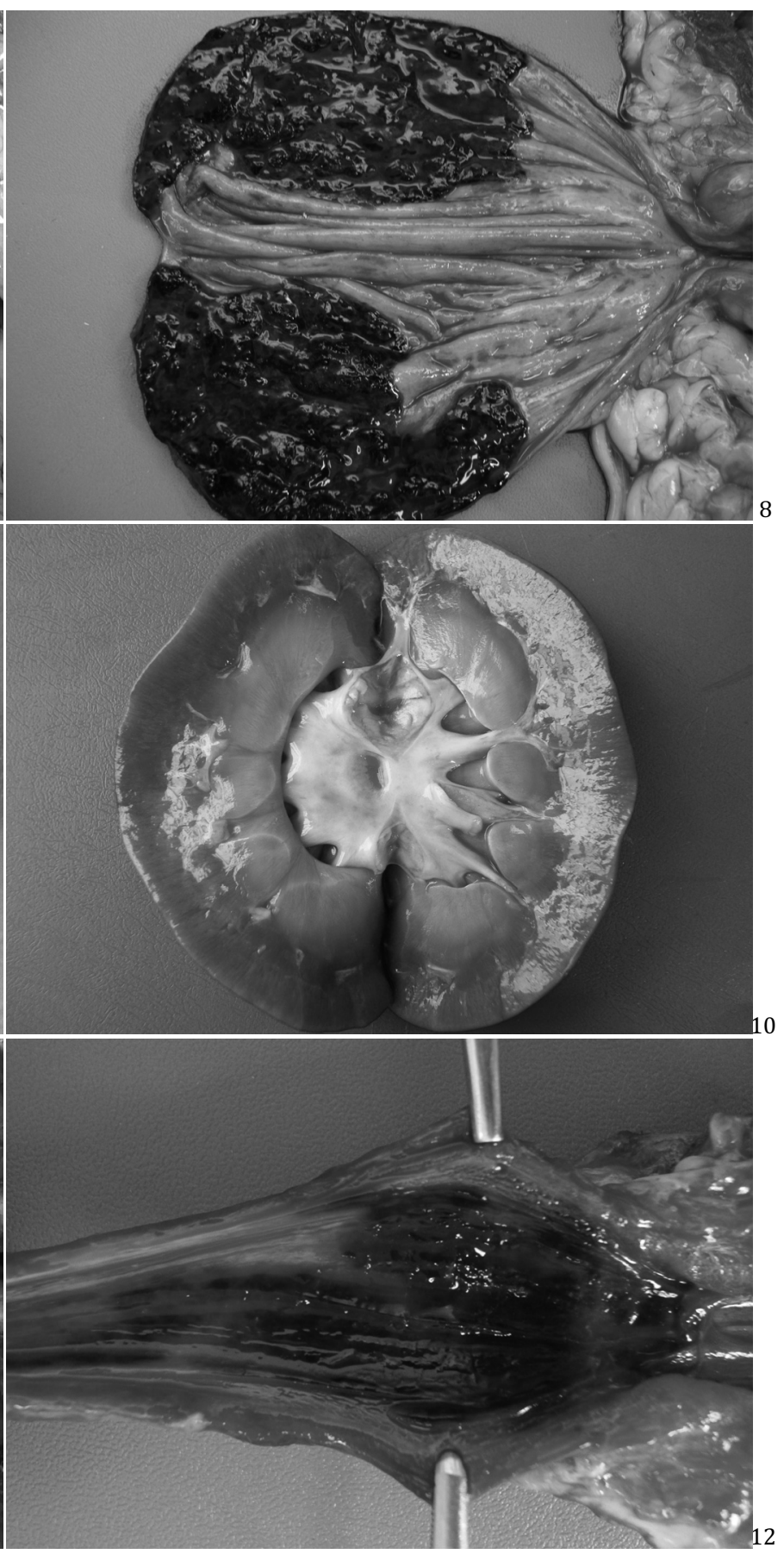

Fig.8. Cistite necro-hemorrágica secundária à uretrólito (cão da Figura 6). A mucosa tem áreas focalmente extensas de necrose e hemorragia acentuadas.

Fig.10. Hidronefrose moderada. Há dilatação moderada da pelve renal associada à atrofia da região medular interna. A lesão é secundária à urolitíase apresentada na Figura11.

Fig.12. Uretrite fibrino-hemorrágica (cão da Figura 6). A mucosa que recobre a uretra está hemorrágica e recoberta por filamentos de fibrina.

hidroureter e hidronefrose $(10 / 76[13,2 \%]$ cada); ruptura vesical/uroperitônio $(6 / 76[7,9 \%]) ;$ pielonefrite $(6 / 76$ $[7,9 \%])$; uretrite $(5 / 76[6,5 \%]) ;$ obstrução vesical $(4 / 76$ 
Quadro 2. Localização anatômica, número de casos e consequências de urolitíase em 76 cães necropsiados no Laboratório de Patologia Veterinária da Universidade Federal de Santa Maria (LPV-UFSM) no período (1990-2010)

\begin{tabular}{|c|c|c|}
\hline $\begin{array}{l}\text { Localização } \\
\text { anatômica }\end{array}$ & $\begin{array}{l}\text { No de } \\
\text { casos }\end{array}$ & Consequências ( $\mathrm{n}^{\circ}$ de casos) \\
\hline Bexiga & 38 & $\begin{array}{l}\text { Cistite (7) } \\
\text { Cistite + pielonefrite (1) } \\
\text { Hidroureter (1) } \\
\text { Hidroureter + hidronefrose (1) } \\
\text { Obstrução vesical + cistite + hidroureter + } \\
\text { hidronefrose + uretrite (1) } \\
\text { Obstrução vesical + cistite + hidroureter + hi- } \\
\text { dronefrose + ruptura vesical + uroperitônio (1) } \\
\text { Obstrução vesical + ruptura vesical + urope- } \\
\text { ritônio (2) }\end{array}$ \\
\hline Rim & 14 & Pielonefrite (2) \\
\hline Uretra & 8 & $\begin{array}{l}\text { Obstrução uretral + dilatação vesical + hi- } \\
\text { droureter + hidronefrose + pielonefrite (1) } \\
\text { Obstrução uretral + ruptura vesical + urope- } \\
\text { ritônio (1) } \\
\text { Obstrução uretral + uretrite + cistite (2) }\end{array}$ \\
\hline Bexiga/uretra* & 7 & $\begin{array}{l}\text { Cistite + uretrite (1) } \\
\text { Obstrução uretral + cistite + pielonefrite (1) } \\
\text { Obstrução uretral + cistite + hidroureter + } \\
\text { ruptura vesical + uroperitônio (1) } \\
\text { Obstrução uretral + cistite + hidroureter + } \\
\text { hidronefrose (1) } \\
\text { Obstrução uretral + dilatação vesical + hi- } \\
\text { droureter + hidronefrose (1) } \\
\text { Obstrução uretral + uretrite + cistite + hi- } \\
\text { droureter + hidronefrose + ruptura vesical e } \\
\text { uretral + uroperitônio (1) }\end{array}$ \\
\hline Rim/bexiga* & 5 & Pielonefrite (1) \\
\hline Rim/bexiga/uretra* & 3 & Hidronefrose (2) \\
\hline Rim/uretra* & 1 & $\begin{array}{l}\text { Obstrução uretral + cistite + hidroureter + } \\
\text { hidronefrose (1) }\end{array}$ \\
\hline
\end{tabular}

*Correspondem a cães que apresentavam urólitos em mais de uma localização anatômica simultaneamente.

[5,2\%]); dilatação vesical $(2 / 76$ [2,6\%]) e ruptura uretral $(1 / 76[1,3 \%])$.

Dos 76 cães, $14(18,4 \%)$ apresentaram obstrução ao fluxo urinário, sendo 11 machos (10 com obstrução uretral e um com obstrução vesical) $(78,6 \%)$ e três fêmeas (três com obstrução vesical) (21,4\%). Dos machos com algum tipo de obstrução $(n=11)$, dois $(18,2 \%)$ apresentaram ruptura de bexiga e um $(9,1 \%)$ apresentou ruptura de bexiga e uretra, concomitantemente. Das fêmeas $(\mathrm{n}=3)$, todas tiveram ruptura de bexiga.

Dos 30 cães que apresentaram lesões secundárias no trato urinário relacionadas à urolitíase, 16 morreram espontaneamente e três foram submetidos à eutanásia em consequência dessas lesões secundárias. Nove cães $(30 \%$ dos cães com lesão secundária [9/30] e 11,8\% do total [9/76]) desenvolveram uremia, caracterizada na necropsia pela presença de lesões extra-renais. Na maior parte dos casos de uremia (7/9 [77,8\%]), a origem foi pós-renal devido à obstrução ao fluxo urinário por urólitos na bexiga e/ou uretra. Em alguns poucos casos de uremia (2/9 $[22,2 \%])$, os urólitos estavam localizados na pelve renal e associados com pielonefrite grave. Nesses dois casos a uremia estava associada à insuficiência renal e, portanto, foi considerada como tendo origem primariamente renal.

\section{DISCUSSÃO}

Urolitíase é uma condição clínica importante e recorrente em cães (Picavet et al. 2007, Rogers 2011). A prevalência da urolitíase em cães neste estudo retrospectivo de casos de necropsia foi de 1,6\%. Entretanto, 19 (25\%) dos 76 cães afetados morreram espontaneamente ou foram submetidos à eutanásia em consequência de complicações relacionadas à urolitíase, o que mostra a relevância dessa condição como causa de morte ou eutanásia nessa espécie animal.

Em cães com urolitíase, a predominância de machos (Del Angel-Caraza et al. 2010) ou de fêmeas (Houston et al. 2000) varia entre os estudos. Se observados os casos em que foram comparados os resultados do tipo de mineral que compõe o urólito com o sexo do cão, nota-se o predomínio de fêmeas com cálculos de estruvita (fosfato amoníaco magnesiano) e de machos com cálculos de oxalato de cálcio (Houston et al. 2004, Picavet et al. 2007, Osborne et al. 2008, Houston et al. 2009, Del Angel-Caraza et al. 2010, Rogers et al. 2011). Em cadelas, a infecção do trato urinário inferior por bactérias produtoras de urease, como, por exemplo, Staphylococcus intermedius e Proteus mirabilis, torna o $\mathrm{pH}$ da urina mais alcalino, o que predispõe a formação dos cálculos de estruvita (Ling et al. 1998).

Neste estudo, os cães machos predominaram (64,5\%), porém a composição química dos urólitos não foi determinada por essa não ser uma prática de rotina no LPV-UFSM. Muitos protocolos continham a descrição macroscópica dos urólitos, mas sabe-se que embora a cor possa dar alguma indicação da composição, ela pode ser variável entre cálculos com a mesma composição química (Newman et al. 2007). As composições químicas mais comuns dos urólitos em cães são estruvita, oxalatos e purinas (uratos, ácido úrico e xantina) e as incomuns incluem sílica, cistina e fosfato de cálcio (Maxie \& Newman 2007).

Em estudos recentes sobre urolitíase em cães, os indivíduos afetados tinham em média cinco ou sete anos de idade (Picavet et al. 2007, Del Angel-Caraza et al. 2010, Rogers et al. 2011). Dentre os 76 cães com urolitíase, a maioria era adulta, com média de idade de cinco anos. Os cães idosos representaram 39,5\% dos casos, enquanto os filhotes apenas 5,3\%. Este resultado é semelhante ao observado em outros estudos (Del Angel-Caraza et al. 2010, Rogers et al. 2011).

Neste levantamento, a maioria dos casos ocorreu em cães com raça definida $(56,6 \%)$ e as cinco raças mais representadas foram: Pastor Alemão, Poodle, Dálmata, Yorkshire Terrier e Boxer. Entretanto, como não se conhece a população dessas raças na área de abrangência do LPV-UFSM, não é possível uma análise adequada deste parâmetro. A prevalência de urolitíase em cães Schnauzer, Shih-Tzu, Bichon Frisé, Poodle, Yorkshire Terrier e Dálmata é considerada alta (Ling et al. 1998, Sosnar et al. 2005, Picavet et al. 2007). Em cães da raça Pastor Alemão, o risco de desenvolvimento de urolitíase é considerado baixo (Ling et al. 1998). Segundo alguns autores, a urolitíase é observada mais frequentemente em cães de raça definida e principalmente de pequeno porte (Houston et al. 2000, Picavet et al. 2007, Del Angel-Caraza et al. 2010, Fleming 2011). Cães 
Dálmatas podem desenvolver cálculos de urato. Isto ocorre devido a uma anomalia hereditária no metabolismo das purinas, que resulta em altas taxas de excreção de ácido úrico (Houston et al. 2000, Aquino et al. 2007). Embora todos os cães dessa raça excretem quantidades relativamente elevadas de uratos na urina, apenas uma pequena percentagem (especialmente machos) formam cálculos de uratos (Osborne et al. 1996).

Os sinais clínicos indicativos de urolitíase e consistindo de hematúria, anúria, disúria e incontinência urinária foram observados somente em cerca de um terço dos cães acometidos. Isto demonstra a dificuldade que há algumas vezes em se estabelecer um diagnóstico clínico de urolitíase que permita uma intervenção rápida e curativa dessa doença.

Como observado no Quadro 2, a principal localização anatômica dos urólitos foi a bexiga (urocistólitos). Em um estudo retrospectivo em que foram analisados 4.495 urólitos de cães e gatos, $78 \%$ dos urólitos de cães e $81 \%$ dos de gatos eram urocistólitos (Picavet et al. 2007). A bexiga é relatada como a principal localização anatômica dos urólitos em cães, seguida pela uretra (uretrólitos) (Escolar et al. 1991, Ling et al. 1998); enquanto os localizados no rim (nefrólitos) representam menos de 4\% (Ling et al. 1998, Shaw \& Ihle 1999, Oyafuso et al. 2010). Neste estudo, entretanto, a localização renal predominou sobre a uretral.

Diretamente ligado à localização anatômica dos urólitos estão os tipos de lesões secundárias ou consequências observadas no trato urinário (Aquino et. al. 2007). Consequências potenciais da urolitíase são danos ao urotélio, infecção do trato urinário e obstrução ao fluxo urinário (Lulich et al. 2004, Wisener et al. 2010). A cistite, que neste estudo foi frequentemente necro-hemorrágica, ocorre porque urocistólitos agridem mecanicamente a mucosa, o que leva à erosão, ulceração e hemorragia, e predispõe à invasão bacteriana da lâmina própria (Shaw \& Ihle 1999, Newman et al. 2007). A obstrução uretral é mais frequente em cães machos do que em fêmeas por terem a uretra mais longa e menos calibrosa (Newman et al. 2007). Os uretrólitos podem causar obstrução principalmente na base do osso peniano (Aquino et al. 2007). Em alguns casos a obstrução urinária por urólitos leva à ruptura da bexiga e/ou da uretra (Maxie \& Newman 2007, Newman et al. 2007). Necrose local por pressão, ulceração da mucosa uretral e uretrite hemorrágica também são achados frequentes (Newman et al. 2007).

Neste estudo, apesar da obstrução total ao fluxo urinário por urólitos ter sido menos prevalente nas fêmeas, consequências graves como ruptura de bexiga as acometeram em todos os casos obstrutivos. Outras consequências frequentes da obstrução ao fluxo urinário foram dilatação vesical, hidroureter e hidronefrose. Essas condições geralmente estão associadas à obstrução parcial ou intermitente ao fluxo urinário (Maxie \& Newman 2007).

A obstrução completa do fluxo em associação à infecção do trato urinário pode resultar em rápida destruição do parênquima renal (pielonefrite). Se a lesão progredir e afetar ambos os rins poderá ocorrer uremia por insuficiência renal (Lulich et al. 2004), como vista em dois cães deste estudo. Obstrução do trato urinário com uremia, como vista em sete cães deste estudo, mais comumente ocorre devido à obstrução da uretra por cálculos pequenos (Newman et al. 2007).

\section{CONCLUSÕES}

Através deste estudo retrospectivo dos casos de urolitíase foi possível concluir que:

A prevalência de urolitíase nos cães necropsiados num período de 21 anos foi de 1,6\%;

A população afetada era constituída predominantemente de cães machos $(64,5 \%)$; adultos $(52,6 \%)$; com raça definida $(56,6 \%)$;

Em um terço dos casos o histórico clínico indicava urolitíase;

Os sinais clínicos que caracterizaram a doença foram hematúria, anúria, disúria e incontinência urinária;

Os locais mais frequentemente acometidos, em ordem decrescente de prevalência, foram bexiga, rim e uretra;

Lesões secundárias à urolitíase foram observadas em aproximadamente $40 \%$ dos cães afetados.

Em 25\% dos cães afetados ocorreu morte espontânea ou eutanásia decorrentes das lesões secundárias à urolitíase;

Em 11,8\% dos cães ocorreu uremia.

Agradecimentos.- M.A. Inkelmann e M.E. Trost são bolsistas da Coordenação de Aperfeiçoamento de Pessoal de Nível Superior (CAPES). G.D. Kommers é bolsista de produtividade em pesquisa (PQ-Nível 2) do CNPq.

\section{REFERÊNCIAS}

Aquino L.C., Martins C.S. \& Galera P.D. 2007. Urolitíase por urato em Dálmatas: revisão de literatura e relato de caso. Clín. Vet. 70:56-66.

Del Angel-Caraza J., Diez-Prieto I., Pérez-García C.C. \& García-Rodríguez M.B. 2010. Composition of lower urinary tract stones in canines in Mexico City. Urol. Res. 38:201-204.

Escolar E., Bellanato J. \& Rodriquez M. 1991. Study of cystine urinary calculi in dogs. Can. J. Vet. Res. 55:67-70.

Fighera R.A., Souza T.M., Silva M.C., Brum J.S., Graça D.L., Kommers G.D., Irigoyen L.F. \& Barros C.S.L. 2008. Causas de morte e razões para eutanásia de cães da Mesorregião do Centro Ocidental Rio-Grandense (19652004). Pesq. Vet. Bras. 28(4):223-230.

Fleming J.M., Creevy K.E. \& Promislow D.E.L. 2011. Mortality in North American dogs from 1984 to 2004: An investigation into age, size and breed-related causes of death. J. Vet. Intern. Med. 25:187-198.

Houston D., Patterson J., Moore A., Smith S., Favrin M., Villagonzalo M. \& Hoff B. 2000. Preliminary results from the Canadian Veterinary Urolith Centre. Can. Vet. J. 41:318-319.

Houston D.M., Moore A.E.P., Favrin M.G. \& Hoff B. 2004. Canine urolithiasis: a look at over 16,000 urolith submissions to the Canadian Veterinary Urolith Centre from February 1998 to April 2003. Can. Vet. J. 45:225230 .

Houston D.M., Andrew E.P. \& Moore A.E.P. 2009. Canine and feline urolithiasis: Examination of over 50,000 urolith submissions to the Canadian Veterinary Urolith Centre from 1998 to 2008. Can. Vet. J. 50:1263-1268.

Ling G.V., Ruby A.L., Johnson D.L., Thurmond M. \& Franti C.E. 1998. Renal calculi in dogs and cats: prevalence, mineral type, breed, age, and gender interrelationships (1981-1993). J. Vet. Intern. Med. 12:11-21.

Lulich J.P., Osborne C.A., Bartges J.W. \& Lekcharoensuk C. 2004. Distúrbios do trato urinário inferior dos caninos, p.1841-1877. In: Ettinger S.J. \& Feldman E.C. (Eds), Tratado de Medicina Interna Veterinária: doenças do cão e do gato. Vol.2. 5 ${ }^{\mathrm{a}}$ ed. Guanabara Koogan, Rio de Janeiro.

Maxie M. G. \& Newman S. J. 2007. The urinary system, p.425-522. In: Maxie 
M.G. (Ed.), Jubb , Kennedy, and Palmer's Pathology of Domestic Animals. Vol.2, $5^{\text {th }}$ ed. Saunders Elsevier, Philadelphia.

Monferdini R.P. \& Oliveira J. 2009. Manejo nutricional para cães e gatos com urolitíase: revisão bibliográfica. Acta Vet. Brasilica 3(1):1-4.

Neta E.S.M. \& Munhoz A.D. 2008. Urolitíase em cães e gatos: uma revisão. MEDVEP 6(17):24-34.

Newman S.J., Anthony W.C. \& Panciera R.J. 2007. Urinary system, p.613691. In: MacGavin M.D. \& Zachary J. F. (Eds), Pathologic Basis of Veterinary Disease. $4^{\text {th }}$ ed. Mosby-Elsevier, St Louis.

Osborne C.A., Lulich J.P., Unger L.K., Bartges J.W. \& Felice L.J. 1996. Urolitíase canina e felina: relação da etiopatogenia com o tratamento e prevenção, p.543-596. In: Bojrab M.J. (Ed.), Mecanismos da Moléstia na Cirurgia dos Pequenos Animais. $2^{\underline{a}}$ ed. Manole, São Paulo.

Osborne C.A. \& Lulich J.P. 2004. The role of nutrition in management of canine and feline urolithiasis. DVM Newsmagazine 6:40-43.

Osborne C.A., Lulich J.P., Kruger J.M., Ulrich L.K. \& Koehler L.A. 2008. Analysis of 451,891 canine uroliths, feline uroliths, and feline urethral plugs from 1981 to 2007: Perspectives from the Minnesota Urolith Center. Vet. Clin. Small Anim. 39:183-197.
Oyafuso M.K., Kogika M.M., Waki M.F., Prosser C.S., Cavalcante C.Z. \& Wirthl V.A.B.F. 2010. Urolitíase em cães: avaliação quantitativa da composição mineral de 156 urólitos. Ciência Rural 40(1):102-108.

Picavet P., Detilleux J., Verschuren S., Sparkes A., Lulich J., Osborne C., Istasse L. \& Diez M. 2007. Analysis of 4,495 canine and feline uroliths in the Benelux: A retrospective study, 1994-2004. J. Anim. Physiol. Anim. Nutr. 91:247-251.

Rogers K.D., Jones B., Roberts L., Rich M., Montalto N. \& Sophie Beckett 2011. Composition of uroliths in small domestic animals in the United Kingdom. Vet. J. 188:228-230.

Shaw D. \& Ihle S. 1999. Doenças do trato urinário e distúrbios hidroeletrolíticos, p.355-420. In: Ibid. (Eds), Medicina Interna de Pequenos Animais. Artmed, Porto Alegre.

Sosnar M., Bulkova T. \& Ruzicka M. 2005. Epidemiology of canine urolithiasis in the Czech Republic from 1997 to 2002. J. Small Anim. Pract. 46:177-184.

Wisener L.V., Pearl D.L., Houston D.M., Reid-Smith R.J. \& Moore A.E.P. 2010. Spatial and temporal clustering of calcium oxalate and magnesium ammonium phosphate uroliths in dogs living in Ontario, Canada between 1998 and 2006. Prevent. Vet. Med. 95:144-151. 